\title{
Investigation on the Effects of Maternity Support Conditions on Reproductive Behavior of Women of Childbearing Age in Beijing
}

\author{
Xingxuan Xi; Huixian Zhang; Lei Meng \\ North China Electric Power University, Changping, Beijing, China \\ 15650756648@163.com; zhxdmfyx@163.com; 18139996636@163.com
}

\begin{abstract}
The implementation of the universal two-child policy has been lasting for more than one year until now. However, there are some families who are unwilling to give birth to children and dare not to give birth to children because of reproductive cost, economic burden, raising burden and other problems. There is a serious social problem that how to make couples give birth to children and raise children easily. This paper will analyze the important factors that will influence the reproductive behavior of women at reproductive age through investigation and research on the current situation of fertility guarantee conditions in Beijing by analytic hierarchy process. Meanwhile, relevant suggestion and measures will be put forward from the public view according to fertility guarantee conditions based on perspectives of promoting social harmonious development and protecting woman's rights. These suggestions and measures can promote fertility guarantee conditions to adapt the implementation of the universal two-child policy.
\end{abstract}

Keywords-Reproductive behavior; maternity insurance; Women at childbearing age; The universal two-child policy; Medical conditions

\section{INTRODUCTION}

Fertility policy is an adjusting policy of population reproduction within a period of time that is established by a nation or a region according to the development of social economy and the bearing capacity of resources and environment. Family planning policy is a basic national policy in our country. The amount of people whose labor age is from 16 to 59 years old has started to reduce since 2012 in China's mainland. The amount of population in 2013 reduced by 2.44 million than last year. The population in 2014 reduced by 3.71 million than last year. According to a prediction, the amount of people who are at labor age will be reducing within a longer time at least until 2030. The variation of population age structure will lead to constant improvement of average age of labor. As a result, the variation will influence vitality of labor. The reduction of labor amount and proportion will necessarily lead to the disappearance of the demographic dividend and increase burden of raising people. However, demographic debt or demographic loss that we can also call demographic reduction will appear soon after the demographic dividend. The decision was made to fully implement the universal two-child policy during the Fifth Plenary Session of the Communist Party of China. After comprehensive implementation of the two-child policy, National Health and Family Planning Commission will intensify efforts to increase supply of service resources, improve treatment ability, strengthen cultivation of scarce talent and create the entire service chain [1]. Deepening the reform of the medical and sanitary system, strengthening the entire basic medical and health care services for reproduction, improving health level of women and children and ensuring the smooth implementation of the comprehensive two-child policy are put forward in some suggestion on strengthening the entire basic health care service jointly proposed by the National Health and Family Planning Commission, the National Development and Reform Commission, the Ministry of Education, the Ministry of Finance and the Ministry of Human Resources and Social Security. In the context of this situation, in order to fully understand current insurance situation of women at reproductive age in Beijing and discuss the effect of fertility protection level in Beijing on the reproductive behavior of women at reproductive age, especially, the effect of health care change on reproductive willingness and action [2], specific advice will be put forward aiming at the reproductive security in the present social security and the promotion of reproductive and medical quality. At last this paper will discuss the effects of the universal two-child policy on reproductive behavior of women at reproductive age.

\section{SURVEY DESIGN}

As a capital city in China, Beijing has certain particularity in politics, economy and society. It also has its own features and complexity in city structure. According to these characteristics, workers who work in the secondary and tertiary industry are mainly in urban functional expanding zone and urban developing zone. The population

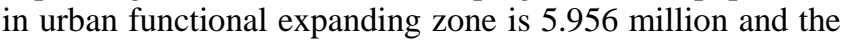
proportion is $53.6 \%$. The population in urban developing zone is 2.469 million and the proportion is $22.2 \%$. The population in capital functional core zone is 2.023 million and the proportion is $18.2 \%$. The population in ecological conservation and development zone is 662 thousands and the proportion is $6 \%$. In order to make sure richness and representation of samples, there are some representative 
places being selected as investigating places, such as the five crossings of Haidian district and Zhongguancun, Huilongguan county in Changping district, Xizhimen in Xicheng district, Wangfujing in Dongcheng district, and the national trade in Chaoyang district. Investigation was finished by a combination of stratified sampling and random sampling. Accumulation of data and analysis of problems were finished mainly by handing out questionnaires and subordinately by documentary collection and interview to do an investigation with women at reproductive age randomly.

\section{ANALYSIS OF INVESTIGATING DATA}

\section{A. Data Analysis Towards Influencing Factors of the} Reproductive Behavior of Women at the Proper Age by the Analytic Hierarchy Process

Analytic hierarchy process is mainly used in qualitative analysis and quantitative analysis. It is used to establish some hierarchies, such as targets, rules, plannings and other hierarchies based on factors that are related to decision-making and do weighting analysis for every hierarchy. Through the selected indicators, we can see that it is a multi-objective problem and involves many factors. And various factors interact with each other. When we use the analytic hierarchy process to deal with complex problems, factor index needs to be analyzed: factors that need to be compared, factors that need to be influenced. And then, all the elements need to be classified. The hierarchical structure model of the interconnection between each factor class is constructed in Figure1.

The hierarchical level of every factor class is determined by the relationship between the factor and the aim. The first hierarchy is the target layer. It means that reproductive behavior influencing ranking. The second hierarchy is the criterion layer. The types of affecting factors that will be involved in the ranking effects of reproductive behavior, including medical services and medical resources, maternity leave and maternity benefits. The third hierarchy is the schematic layer. This layer is used to evaluate affecting factors and evaluation index in the criterion layer, including medical technology, maternal and child health system, maternity insurance reimbursement channel, hospital configuration, Maternal and infant situation, unit nature, work needs, enterprise wage level and so on

\section{B. Analysis of results}

We tested consistency of the model and get the weighting analytic results. Through the analysis of analytic hierarchy process (AHP model), the weighting of three factors that influences the reproductive behavior of women at reproductive age is $\mathrm{B} 1$ (medical services and medical resources) $=0.5714, \quad \mathrm{~B} 2$ (maternity leave) $=0.2857, \quad \mathrm{~B} 3$ (maternity benefits $)=0.1429$, which are shown in the following table:

TABLE I.

INFLUENCING FACTOR ANALYSIS OF REPRODUCTIVE BEHAVIOR

\begin{tabular}{|c|c|c|c|c|c|c|}
\hline \multicolumn{7}{|c|}{ Judgment matrix of reproductive behavior influence A-Bi } \\
\hline & $\begin{array}{l}\text { Medical } \\
\text { services and } \\
\text { medical } \\
\text { resources }\end{array}$ & Maternity leave & $\begin{array}{l}\text { Maternity } \\
\text { benefits }\end{array}$ & $\begin{array}{l}\text { Weighting } \\
\text { index }\end{array}$ & Ranking & \\
\hline $\begin{array}{l}\text { Medical services } \\
\text { and medical } \\
\text { resources }\end{array}$ & 1 & 2 & 4 & 0.5714 & 1 & \\
\hline Maternity leave & $1 / 2$ & 1 & 2 & 0.2857 & 2 & \\
\hline Maternity benefits & $1 / 4$ & $1 / 2$ & 1 & 0.1429 & 3 & \\
\hline & $\mathrm{CI}=0.0005$ & $\mathrm{RI}=0.58$ & $\mathrm{CR}=0.00086$ & & & \\
\hline \multicolumn{7}{|c|}{ Judgment matrix of medical services and medical resources $\mathrm{Ci}$} \\
\hline & Reimbursement & $\begin{array}{l}\text { Medical } \\
\text { technology }\end{array}$ & $\begin{array}{l}\text { Maternal and } \\
\text { child health } \\
\text { system }\end{array}$ & $\begin{array}{c}\text { Hospital } \\
\text { configuration }\end{array}$ & $\begin{array}{l}\text { Weightin } \\
\text { g index }\end{array}$ & Ranking \\
\hline Reimbursement & 1 & $1 / 2$ & 4 & 2 & 0.3060 & 2 \\
\hline $\begin{array}{c}\text { Medical } \\
\text { technology }\end{array}$ & 2 & 1 & 2 & 4 & 0.4328 & 1 \\
\hline $\begin{array}{l}\text { Maternal and } \\
\text { child health } \\
\text { system }\end{array}$ & $1 / 4$ & $1 / 2$ & 1 & $1 / 2$ & 0.1082 & 4 \\
\hline $\begin{array}{c}\text { Hospital } \\
\text { configuration }\end{array}$ & $1 / 2$ & $1 / 4$ & 2 & 1 & 0.1530 & 3 \\
\hline & $\mathrm{CI}=0.0052$ & $\mathrm{RI}=0.90$ & $\mathrm{CR}=0.0058$ & & & \\
\hline \multicolumn{7}{|c|}{ Judgment matrix of maternal leave $\mathrm{Ci}$} \\
\hline
\end{tabular}




\begin{tabular}{|c|c|c|c|c|c|c|}
\hline \multicolumn{7}{|c|}{ TABLE 1 , cont. } \\
\hline & $\begin{array}{l}\text { Situation of } \\
\text { maternal and } \\
\text { child }\end{array}$ & $\begin{array}{l}\text { Nature of } \\
\text { enterprises }\end{array}$ & Working needs & $\begin{array}{l}\text { Weighting } \\
\text { index }\end{array}$ & Ranking & \\
\hline $\begin{array}{l}\text { Situation of } \\
\text { maternal and } \\
\text { child }\end{array}$ & 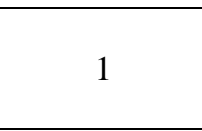 & $1 / 2$ & 4 & 0.3764 & 2 & \\
\hline $\begin{array}{c}\text { Nature of } \\
\text { enterprises }\end{array}$ & 2 & 1 & 2 & 0.4743 & 1 & \\
\hline Working needs & $1 / 4$ & $1 / 2$ & 1 & 0.1494 & 3 & \\
\hline & $\mathrm{CI}=0.0015$ & $\mathrm{RI}=0.58$ & $\mathrm{CR}=0.0026$ & & & \\
\hline \multicolumn{7}{|c|}{ Comprehensive judgment of B-C layer } \\
\hline $\mathrm{C} / \mathrm{B}$ & $\begin{array}{c}\text { Medical } \\
\text { services and } \\
\text { medical } \\
\text { resources }\end{array}$ & Maternity leave & $\begin{array}{l}\text { Maternity } \\
\text { benefits }\end{array}$ & $\mathrm{CW}$ & Ranking & \\
\hline $\begin{array}{c}\text { Bi weighting } \\
\text { layer }\end{array}$ & 0.5714 & 0.2857 & 0.1429 & & & \\
\hline Reimbursement & 0.3060 & 0 & 0 & 0.1748 & 2 & \\
\hline $\begin{array}{c}\text { Medical } \\
\text { technology }\end{array}$ & 0.4328 & 0 & 0 & 0.2473 & 1 & \\
\hline $\begin{array}{l}\text { Maternal and } \\
\text { child health } \\
\text { system }\end{array}$ & 0.1082 & 0 & 0 & 0.0618 & 7 & \\
\hline $\begin{array}{c}\text { Hospital } \\
\text { configuration } \\
\end{array}$ & 0.1530 & 0 & 0 & 0.0874 & 6 & \\
\hline $\begin{array}{l}\text { Situation of } \\
\text { maternal and } \\
\text { child } \\
\end{array}$ & 0 & 0.3764 & 0 & 0.1075 & 5 & \\
\hline $\begin{array}{c}\text { Nature of } \\
\text { enterprises }\end{array}$ & 0 & 0.4743 & 0 & 0.1355 & 4 & \\
\hline Working needs & 0 & 0.1494 & 0 & 0.0428 & 8 & \\
\hline $\begin{array}{c}\text { Corporate wage } \\
\text { level }\end{array}$ & 0 & 0 & 1 & 0.1429 & 3 & \\
\hline
\end{tabular}

1) Factors of medical services and medical resources

Medical services and medical resources factors contain medical technology (0.4328), reproductive reimbursement (0.306), hospital configuration (0.153) and maternal and child health system $(0.1082)$.

When giving birth to a child, women at reproductive age may select hospitals that are in different levels because of different ages. During individual interview, we can know that elderly puerperae will be inclined to select hospitals that possess high medical technology level and high comprehensive level because of the high risk of childbearing.

Then, process of reimbursement will influence woman's reproductive behavior. Over-complex reimbursement of reproductive medical costs may reduce the occurrence of reproductive behavior because current reimbursement of reproductive medical costs is tending to be complex and disordered for women who have lower economic capacity and are not from Beijing.
Differences of woman's reproductive behavior were intensified because of imperfect filing system of puerperae, unbalanced configuration of medical resources, very unbalanced number of seeing doctors in different-level hospitals. The effect of maternal and child health system is weak. It also means that maternal and child health system in our nation is still imperfect.

\section{2) Maternity leave factors}

Maternity leave contains the nature of enterprises (0.4743), situation of maternal and child (0.3764), the degree of working needs (0.1494).

In terms of the nature of enterprises, maternity leave of state enterprises is much longer on average [3]. Private enterprises will reduce maternal leave of workers, so female workers in different enterprises have different reproductive behaviors. Maternity leave of parturient women who are in dystocia is much longer than that of parturient women who are in eutocia, which is also determined according to the health of maternal and child. Working needs and importance of jobs will have less influence on reproductive behavior. 


\section{3) Maternity benefits factors}

Maternity benefits influence less on woman's reproductive willingness [4]. In the sample, $40 \%$ of people thought that maternity benefits will influence the fertility desire, but the influence is weak. However, 34\% of people thought that there is no influence on fertility desire. Power of benefits has no substantial effects on reproductive willingness because of generally high wage level in Beijing and basically high living standard.

\section{COUNTERMEASURES ON STRENGTHENING REPRODUCTIVE}

\section{BeHAVIOR GuARANTEE OF WOMEN AT REPRODUCTIVE AGE}

\section{A. Relieve Contradictions of a Structural Shortage of Resources of Reproductive Medical Health Services}

The first one is adjusting maternity beds in hospitals. The number of maternity beds should be expanded, the beds resources of departments should be integrated and the problems of the shortage of beds, which are caused by the increasing of pregnant women and puerperae, should be relieved as soon as possible under the universal two-child policy by using the existing medical resources.

The second one is optimizing hierarchical filing system. Pregnant and parturient women need to be classified reasonably by establishing filing service center so that supply and demand contradiction that the hospital is crowded and pregnant and parturient women have no bed can be relieved. As a result, every pregnant and parturient woman can get timely, safe and efficient services.

The third one is improving service ability of primary health care institutions, completing the health service system for reproductive health care, promoting the balanced development of medical services among regions, and enhancing all medical service ability during fertility process. All level medical institutions need to be supervised to complete medical quality and the security system, strengthen medical quality management and control system and strictly regulate clinical service behaviors.

\section{B. Fully Strengthening Cultivation and Use of Urgently-Needed Professional Talents}

The training of obstetricians, midwives and pediatricians needs to be accelerated. In the training of primary medical workers, the training of knowledge and skills of maternal and child health should be enhanced. Maternal and child health institutions which satisfy the needs should be organized to actively undertake the task of the standardized training of residents. These institutions should also strengthen training of the professional content of maternal and child health and built a compound talents team whose members have a solid foundation in clinical medicine and wide public sanitary views. Performance evaluation of medical sanitary institutions and talents' encouraging system needs to be enhanced. Salary and benefits of the medical staff should be improved. Job attraction needs to be increased.

\section{Formulating a Unified National Maternity Insurance Law, Improving the Legislative Level of Maternity Insurance and Increasing Protection of the Labor Rights of Women who Have Two Children}

Maternity insurance has never been legislated independently until now. Carrying out maternity insurance work is based primarily on methods for the trial of maternity insurance for enterprise employees that were developed by the Ministry of Labor in 1994 and later on constant enactment of local regulations. The force of these methods and regulations is not enough and the flexibility of these methods and regulations is very strong. Enterprises implements maternity insurance policy without specification. These is also a serious phenomenon that a lot of workers did not pay for insurance and even refunded insurance. Meanwhile, maternity guarantee conditions of a lot of people who are from other cities are very concerning because of complex demographics in Beijing. As a result, establishing a national and unified birth insurance law is good for building maternity insurance mode within the whole nation [5]. Improving the status of maternity insurance is good for staff mobility.

\section{Reforming Payment Mode of Maternity Insurance Premium and Combining Rights and Obligations}

Present payment subjects can be reformed to individuals and enterprises so that two parties can jointly pay and undertake tax burden of enterprises according to the rule of rights and obligations are equal [6]. Under present payment mode, people who have insurance are usually enjoying the rights without fulfilling the obligations of payment. It is against from the rule of rights and obligations are equal. Sharing payment can reduce enterprises' burden, at the same time, the burden of the individual will not be heavy [7]. For non-workers who pay insurance individually, they can refer to the policy of participating in the flexible employment health insurance and the residents' health insurance. After satisfying payment conditions, they can also get maternity benefits.

\section{E. Predicting and Monitoring Seriously Newly-Born Population in the Context of Universal Two-Child Policy}

The implementation of universal two-child policy will result in fast increase of the amount of newly-born population. Improving accuracy of predicting and monitoring newly-born population in in the context of universal two-child policy can optimize medical resources configuration [8]. It can also provide data support to deal with the imbalance between supply and demand of medical services, supply of beds, medical staff configuration and other aspects. It can enhance information feedback ability and set the stage for the timely and accurate settlement of the efficiency and fairness of maternity protection. 


\section{F. Extending Appropriately Breastfeeding Time and Paternity Leave, Adding Two-Child Parental Leave and Two-Child Grants According to the Laws and Developing Children Care Services}

The time for puerpera to breast-feed is from the end of maternity leave until the child is one year old and puerperae can have one hour to do breastfeeding according to the regulation of breastfeeding time in our nation. If the child is weak, puerperae can apply for no more than 6-month breastfeeding leave. Extending one-hour breastfeeding time can satisfy mothers and children better.

There is different length of paternity leave in different provinces in our nation. The longest paternity leave is 30 days. The shortest one is 7 days. And paternity leave is not popularized until now. Extending paternity leave appropriately is good for health of mothers and children and neonatal intelligence development. It is good for establishing harmonious social relations and employment equality. The change of traditional social division of labor will further eliminate the issue of discrimination against women in employment, and also help to create a social status of equality between men and women. Couples can take paternity leave off with wage in Swedish and Japan. Our nation can add two child parental leaves and two-child grant so that couple can have less economic costs and time costs. The rights of female workers need to be preserved during the pregnancy period, maternal period and breastfeeding period [9] so that the contradiction between female workers and enterprises can be relieved.

At the same time, 0-3 years old children care is not perfect enough [10]. This situation strengthened the contradiction between woman's work and household work. Improving public children care equipment and services of 0-3 years old children can provide more safe and affordable public children care services for families so that raising burden can be relieved.

\section{CONCLUSION}

According to analysis of investigating results, medical services and medical resources are the biggest factors that will influence reproductive behavior of women at productive age in Beijing within fertility guarantee conditions. The next is maternity leave and maternity benefits. However, medical services and medical resources are relatively scarce currently, so government needs to optimize resources configuration at the aspect of medical services and resources.

\section{REFERENCES}

[1] Z. Z. Zheng, Chinese women of childbearing age willing study, China population science, vol.5,pp.1-8,2004.

[2] F. Y. Jia, The analysis of potential impact of Selective Two Children policy to women of child-bearing age Kun Shan city, Chinese journal of family planning study, vol.22, No.8, 2014

[3] J. Lin, Discussion on Career Security Problem of Chinese Women at Child-bearing Age, Modern Management, PP. 29-34,2011

[4] J. Zheng. The Study on the Relationship Between Fertility Intentions and Fertility Behavior of Second Child Birth Pioneer. Shan Xi Shan Xi Normal University, pp. 33-36, 2015.

[5] L.N. Ge. Birth insurance system and the construction of a harmonious society, China Health Insurance, vol.10,pp.41-43, 2012.

[6] J. Pan, History and Present Situation of China's Fertility Insurance System. Demographic research, PP. 29-35, 2003

[7] T. Yuan, Improve the creative thinking of birth insurance need, China Health Insurance, vol.10, pp.72-72, 2012.

[8] Z. W. Zhai, X. L. Zhang, Y. A. Jin, An Immediate and Comprehensive Release of the Demographic Consequences of a Child's Policy, Demographic research,pp.3-17,2014

[9] W. W. Chen, coping strategies of human resource management law works under universal two-child era, Human Resource Management, vol.2, pp.12-13, 2016.

[10] H. P. Lv. China's Fertility Policy: the Change and Adjustment of the Future, Population and Society, vol.04, pp.12-21, 2015. 